\title{
Application of Digital Media Art in Architectural Decoration Design in Industrial 4.0 Era
}

\author{
Yang Mou \\ Yibin Vocational and Technical College \\ Yibin, China
}

\author{
Limei Guo \\ Yibin Vocational and Technical College \\ Yibin, China
}

\author{
Junjie Huang \\ Yibin Intermediate People's Court \\ Yibin, China
}

\begin{abstract}
Nowadays, the rapid development of Internet technology and the introduction of concept of Industrial 4.0 Era have rendered a strong push to the development of design art. And among which, the development of digital technology and media has brought about broader space to designers to show their talents, thus the rapid development of digital media art is promoted. And architectural decoration design is also undergoing great changes in terms of both design concept and design results. Designers and consumers are paying more attention on the application of digital media art in architectural decoration design. Therefore, it is necessary to research the application of digital media technology in architectural decoration design.
\end{abstract}

Keywords-Industrial 4.0 Era; digital media art; architectural decoration design; application

\section{INTRODUCTION}

People mainly consider the decorative artistic design of appearance in the traditional application research concept of architectural decoration design. But with the economic development in China, people tend to pay more attention to design connotation and practicability, which has brought new serious test to architectural decoration design. With the continuous development of China's urbanization process, architectural decoration design becomes to be mixed style and disorderly. As a result, people began to realize that architectural decoration design needs to be innovated. However, the traditional design technology is obviously unable to meet the needs of modern art design, and the new type of digital media technology is naturally introduced and applied in architectural decoration design.

\section{INDUSTRIAL 4.0 ERA}

\section{A. Concept of Industrial 4.0 Era}

The concept of Industrial 4.0 Era was first proposed at HANNOVER MESSE by German Federal Teaching and Research Department and the Federal Ministry of Economics and Technology in 2013. Its purpose is to support the research and innovation of a new generation of revolutionary technology in the industrial field, which describes the vigorous promotion of Internet by industry and the application of Internet service technology in manufacturing, so as to cope with the challenge brought by new technology revolution to preempt the commanding point of information technology and the technology in industrial integration development. Industrial 4.0 projects can mainly be divided into two parts: one is "smart factory" focusing on the research on intelligent manufacturing systems and processes, as well as the realization of the network distributed manufacturing facilities; the other is "smart production" mainly relating to the production logistics management, human-computer interaction, and application of 3D technology in industrial production process, etc. of the whole enterprise. The process of industrialization is to subdivide production relations using professional techniques and tools, so as to improve the production quality and speed up the process of product upgrading.

\section{B. Concept of Industrial 4.0 Era of Architectural Decoration Design}

The development of Industrial 4.0 in architectural decoration design industry is accompanied by the extensive application of advanced design techniques and tools. In China, the advent of Industrial 4.0 Era has brought about the intelligent production mode to decoration industry. The difference between it and the traditional design production mode lies in its intelligence and Internet + thinking mode. Use digital technology and media space virtual system to analyze and optimize the design production mode and obtain huge design production data, as well as control and manage the production process of design product through analysis of big data. Such intelligent production mode will inevitably put forward new demands to architectural decoration design. Digital media art is entering into the architectural decoration design industry quietly.

Industrial 4.0 Era of architectural decoration design is characterized by the intelligent design behavior and design 
process. Upon the personalized design plan is formulated according to customer's demand, the design process needs to be organized and managed. First of all, send the design demand by means of digital media, and then set up information management platform. Establish independent digital technology design and management structure by screening and optimizing according to different project requirements, give full play to the advantages of digital media information to organize and allocate design resources rationally, so as to improve the design efficiency.

\section{Digital Media ART}

\section{A. Concept of Digital Media Art}

Nowadays, Industrial 4.0 Era has come, and the digital media art is formed based on digital technology and modern media technology. It can integrate people's rational thinking and the perceptual thinking of art very well, which is a kind of new art form. Compared with other forms of art, it has solved the difficulties of hand-brain integration. The application and expression forms of digital media art include the visual art or design works created by virtue of digital technology and digital media. The most critical point of digital media art differing from other art forms is its expression form or creation process must use digital technology in full or in part.

Digital media art is the most promising art in current art design. It covers digital image art, virtual reality art, Internet + art and many other forms of art. Digital media art is the comprehensive art form from plane to three-dimensional and from form to content. Therefore, digital media art is the unity integrating digital technology, media communication and art design.

\section{B. Characteristics of Digital Media Art}

1) The digital design creation: The creation design of digital media art is conducted based on computer digital platform, which has broken the traditional creation method. But the digital media art does exclude traditional design method. And the works generated are independent, without attaching to other design works.

2) Interactivity of design works: With the vigorous development of digital media art in recent years, the emergence of open type design has made design interaction an indisputable fact. The interactivity of digital media has provided a good condition for the owner's active participation in design, making the owner connect with design works. And the design with owner's participation can change the role fundamentally. The owner can put forward suggestions according to his own requirements, and even change the effect of the works. Thus the requirements for designers will also be more and more stringent.

3) Universality of design subjects: As an emerging art, the expression ability of digital media by virtue of computer technology has exceeded that of the traditional art forms greatly, such as drawings. With the development of digital media, especially the strengthening of image artistic expression and the increasingly enriched processing means has provided a broad platform for digital media art design creation. Therefore, the digital media art with design creation as its purpose is rendered with a broader space in terms of subject selection.

\section{InTRODUCTION OF Digital MEDiA ART OF INDUSTRIAL 4.0 ERA INTO ARCHITECTURAL DECORATION DESIGN}

At present, the digital media has a very wide range of applications, as it can conduct effective acquisition, processing and transmission of the information such as voice, images and text. Ivan Sutherland integrated computer technology and graphic art for the first time in Massachusetts Institute of Technology in 1963. Although the effect is not ideal and has not yet reached the expected results, it is a major breakthrough to combine rational thinking and artistic thinking. Since then, the digital technology has a growing influence on design, and the digital technology is almost used in all the two-dimension design and three-dimension design, including the familiar architectural decoration design.

The digital media art has entered into China as early as 1980 s. And it has become very mature by the end of 1990s, emerging many excellent design works, designers and design companies. Now, with the advent of Industrial 4.0 Era, digital media art has become a kind of modern art design with high development potential, such as digital video, virtual reality, Internet + art, etc. The application of digital media art in architectural decoration design will be more and more mature to show a new architectural style.

\section{Application OF Digital Media ART in ARCHITECTURAL DECORATION}

\section{A. Architectural Decoration Design's Development Depends on Digital Media Art}

1) Architectural decoration design and the development of science and technology are inextricably linked: Architectural decoration design is influenced by technology, aesthetics and urban planning, among which technology is the most important, for example, the adornment design of Crystal Palace Exhibition and Shanghai World Expo, as well as today's excellent decoration designers represented by Liang Zhitian and Joyseph Sy, are all inseparable from the development of science and technology.

2) Architectural decoration design is conducted with the background of social reality: Architectural decoration design is to meet the needs of people's life and aesthetic, rather than simply designed for design, to make design integrate with people's life, meet the humanistic demand and be accepted by people. Now, the Industrial 4.0 Era has brought digital media into people's lives. Thus people's basic necessities of life and even the living style are all closed related to digital media art, and gradually enter into the people's spiritual world from the physical world. People living in the city are longing for the new life and architectural decoration brought by digital media art. Therefore, architectural decoration design depends on digital media art. 


\section{B. Implementation of Architectural Decoration Design in Digital Media Art}

Digital media art started relatively late in China, and the digital decoration design is still in its infancy, many designers still have limitations about their understanding on technical or artistic level. Some people even think that digital media art can only be used for drawing and rendering effect. With the gradual development of digital media art, designers should aware that digital art is a kind of brand-new design idea. In architectural decoration design, digital media art has already integrated into all aspects of architectural decoration design not only from originality, design form as well as design expression.

1) Creative process: Digital media not only change the application of design tools used by the architectural decoration designers, the creation ideas and thinking also change along with it. To draw using mouse instead of pencil and rubber, and make the effects of design picture and space layout be displayed on computer screen compressively, thus the designers' creation inspiration can be inspired, and the imagination be broadened subtly, to generate excellent design works. So, the application of decoration design in the process of creative process is to make the space layout more visualized. The current two-dimensional plane and threedimensional technology have been unable to meet the digital media art's development in the decoration design. Designers should break the traditional design concept, to seek the more open design ideas.

2) Design forms: In the Industrial 4.0 Era, people are trying to make better application of digital media art in the design of architectural decoration. a) Forms of inclusiveness: Digital media art has enabled people to break the limit of time and space for common development. Therefore, decoration designers should also absorb different cultures with a heart of tolerance to lay a basis for the design in the future, and show people the charm of different cultures; $b$ ) Forms of interaction: Interaction design is essential in decorative design, and it is also the necessary design expression. Digital media art make designs more sensitive to people's needs, and customers can feel thoughts and ideas to be expressed by the decoration design more intuitively, to communicate with designers spiritually. But along with the rapid development of digital media, people can even be involved in the decoration design, which has changed the designer's unilateral design form of traditional decoration design and enhanced the interaction and experience of design.

3) Design method: Nowadays, digital media art has been applied to each phase of the architectural decoration design, including research, design scheme and finalize in addition to drawing, which has shared most of the work of designers. Therefore, it can be said that in digital media era, decoration design depends on not only the brain of a designer, but also the designer's ability to use digital media. Customers can participate in the design process, exerting their subjective initiative as customers.

4) Design expression: Digital media art can comprehensively reflect the designer's design intention, which has got rid of the constraint of traditional design expression, to realize three-dimensional design effect using such design software as 3DMax, BIM and Sketch Up. It differs from the traditional plan, design sketch and even the sand table, because it can make people watch the designer's design as if they are personally on the scene, to offer a more complete plan.

\section{DEVELOPMENT DiRECTION OF NEW MEDIA ART DESIGN IN DECORATION DESIGN}

The main development direction of multimedia art in the future is virtual reality technology, which is to simulate a real 3D or 4D environment using computer, enabling people to feel like they are personally on the scene, to truly feel in the scene integrating hearing, sight and touch, thus to realize efficient transfer of information. Virtual reality technology can show the architectural decoration design results in a more comprehensive manner. Such effect cannot be matched by $3 \mathrm{D}$ model or design sketch.

Architectural decoration design combines rational thinking and artistic perceptual thinking; yet virtual reality technology can influence these two aspects. First of all, it can support the designer's rational thinking, enabling him to have a better planning in terms of space layout; moreover, it also can reduce the limit in the design and inspire the designers' imagination; again, it also can make the designer get rid of the constraint of traditional design, and describe and modify the design scheme in a more specific and faster manner, to expression the design scheme in his mind into specific designs to the largest extent.

\section{CONCLUSION}

To sum up, architectural decoration design is the design combining cultural connotation and public life. The development of digital media in Industrial 4.0 Era has changed people's ideas, and the intervention of digital media art has brought the obvious changes in architectural decoration. With the progress of science and technology, decorative design will be more mature. Thanks to its features of comprehensiveness and interaction, digital media art will play a more and more important role in decorative design in the future.

\section{REFERENCES}

[1] Li Sida. Introduction to Digital Media Art [M]. Beijing: Tsinghua University Press, 2006

[2] Wang Xiwen. Industrial 4.0: The Last Industrial Revolution [M]. Electronic Industry Press, 2015:13-14

[3] Tian Jie. Research on Application of Digital Media Art in Architectural Landscape Design [J]. Art and Literature for the Masses, 2012

[4] Wu Dan. Discussion on Application of Digital Media Art in Urban Planning [J]. Big Stage, 2012

[5] Meng Shuai. Study on the Development of Interior Decoration Design in "Industrial 4.0 Era" [J]. Interior Architecture of China 2015(11) 